\title{
EPISTEMOLOGIA BARROCA DE TRISTE FIGURA: DOM QUIXOTE COMO UM EXEMPLO DA TRANSFORMAÇÃO DA EPISTÈMÊ DO SÉCULO XVII A PARTIR DE AS PALAVRAS E AS COISAS DE FOUCAULT
}

\author{
Luís Francisco Fianco Dias*
}

Resumo: O presente texto tem como tema a representação do personagem e da obra de Cervantes, Dom Quixote, dentro da reflexão de Michel Foucault sobre a transformação dos modelos epistemológicos da civilização ocidental na passagem do Renascimento para o Classicismo presente nos primeiros capítulos de sua obra $A s$ Palavras e as Coisas. Para tanto, usaremos, além dos textos já citados de Foucault e de Cervantes, um conto do escritor argentino Jorge Luís Borges referido por Foucault, El Idioma Analítico de John Wilkins, bem como o livro de Jean Calmon O Dom Quixote de Foucault, entre outros.

Palavras-chave: Dom Quixote; Michel Foucault; As Palavras e as Coisas;Epistèmê barroca.

Baroque epistemology of sad figure: Don Quixote as an emblematic character of the transformation of seventeenth century's epistèmê from Foucault's the words and things

Abstract: This paper has as its theme the representation of the character and work of Cervantes, Don Quixote, in the Michel Foucault's reflection on the transformation of the epistemological models of Western civilization in the passage of the Renaissance to the present Classicism in the first chapters of his book The Order of Things. Therefore, we will use, in addition to the aforementioned texts by Foucault and Cervantes, a short story by the Argentinian writer Jorge Luis Borges referred by Foucault, The

* Professor do Programa de Pós-graduação em Letras, do Curso de Filosofia e da Área de Ética e Conhecimento da Universidade de Passo Fundo, RS. Recebido em: 19/09/2015 - Aceito em: 22/04/2016. 
|272 |

Epistemologia Barroca de Triste Figura

Analytical Language of John Wilkins, and the book by Jean Calmon O Dom Quixote de Foucault, among others.

Keywords: Don Quixote; Michel Foucault; The Order of Things; Baroque epistèmê.

Epistemología barroca de triste figura: Don Quijote como carácter emblemático de la transformación de la epistèmê en el siglo xvii segundo las palabras y las cosas de Foucault

Resumen: Este trabajo tiene como tema la representación de la figura y la obra de Cervantes, Don Quijote, en la reflexión de Michel Foucault sobre la transformación de los modelos epistemológicos de la civilización occidental en el paso del Renacimiento hasta el Clasicismo en los primeros capítulos de su obra Las Palabras y las Cosas. Por lo tanto, vamos a utilizar, además de los textos ya citados de Foucault y Cervantes, un cuento del escritor argentino Jorge Luis Borges a lo qual se refiere Foucault, El idioma analítico de John Wilkins, y el libro de Jean Calmon O Dom Quixote de Foucault, entre otros .

Palabras clave: Don Quijote. Michel Foucault. Las Palabras y las Cosas. Epistèmê barroca.

Ainda que o personagem e a obra de Dom quixote sejam caros a Foucault em diversos textos ao longo de suas fases de produção é em As Palavras e as Coisas que nos concentraremos para mostrar, como neste texto, o autor examina os processos de transformação nos modelos de pensamento da modernidade ocidental ao longo dos séculos XVI e XVII, de maneira a tentar compreender as transformações na epistèmê desse período entendida não enquanto simplesmente um saber manifesto, e sim enquanto um conjunto de estruturas e categorias subliminares, quase inconscientes, dentro das quais este conhecimento se movimenta, surge, se transforma e sobre as quais se fundamenta, ainda que esteja sempre dentro desta estrutura maior que a epistèmê configura. Junto com outras diversas transformações, como a sensibilidade estética e a teoria do conhecimento, os sistemas de valores e os modos de estudo das ciências naturais, transformou-se igualmente a literatura e a sua relação com a linguagem. E para tanto, ele usa como metáfora da gênese desse novo modelo de relação semântica com o texto literário o texto de Cervantes, Dom Quixote, o que nos permite traçar algumas considerações a respeito desta 
obra enquanto uma metáfora da literatura ocidental moderna, acompanhando a argumentação de Foucault. Nesse sentido, é importante que retracemos o percurso argumentativo que leva da conceptualização dessas transformações no pensamento moderno até sua exemplificação na literatura pela obra de Cervantes.

\section{1 - O empório celestial dos saberes benévolos}

Foucault inicia já o Prefácio de sua obra nos trazendo pensamentos perigosos. Para tanto ele lança mão de um trecho de Borges que, apesar de não estar nitidamente referenciado, é de fácil localização. Trata-se do ensaio El Idioma Analítico de John Wilkins, publicado pela Primeira vez na obra Otras Inquisiciones, no qual o argentino descreve a linguagem artificial criada pelo polímata que dá nome ao texto, bem como cita outros que se dedicaram à mesma empreitada, inclusive exemplificando suas classificações para, por fim, demonstrar como "descontadas las palabras compuestas y las derivaciones, todos los idiomas del mundo (sin excluir el volapük de Johann Martin Schleyer y la romántica interlingua de Peano) son igualmente inexpresivos". (BORGES, 2015, s. p.) Ou seja, a linguagem é entendida aqui como uma organização arbitrária e provisória, geralmente inexata e incapaz de realizar adequadamente a ligação entre as palavras e as coisas, conforme o próprio Borges conclui mais adiante em seu texto: "He registrado las arbitrariedades de Wilkins, del desconocido (o apócrifo) enciclopedista chino y del Instituto Bibliográfico de Bruselas; notoriamente no hay clasificación del universo que no sea arbitraria y conjetural. La razón es muy simple: no sabemos qué cosa es el universo." (BORGES, 2015, s. p.) Em outro conto de Borges, La Biblioteca de Babel, publicado em 1941, se dá a comparação entre uma biblioteca e o universo, na medida que este possa representar uma imensa biblioteca repleta de inumeráveis livros que são, porém, indecifráveis, o que faz da linguagem não ao acesso ao sentido do universo, e sim uma fabulação sobre ela mesma, em um movimento perpétuo de tautologias e auto-interpretação. 
El universo (que otros llamam la Biblioteca) se compone de un número indefinido, y talvez infinito, de galerías hexagonales, con vastos pozos de ventilacíon en el medio, cercados por barandas bajíssimas. [...] Como todos los hombres de la Biblioteca, he viajado en mi juventud; he peregrinado en busca de un libro, acaso del catálogo de catálogos; ahora que mis ojos casi no pueden descifrar lo que escribo, me preparo a morir a unas pocas leguas del hexágono en que nací. (BORGES, 1997: 86 e 87).

Dessa maneira, a busca de conhecimento pela decifração do universo se torna vã se cotejada com a sua vastidão incomensurável, com a sua indecifrabilidade, de maneira que a linguagem possa, ainda que precariamente, apenas estabelecer relações semânticas internas ao mundo que vai criando ao enunciar. E é justamente esta arbitrariedade que nos devolve ao idioma analítico de John Wilkins, do qual um dos trechos mais perturbadores do ensaio, e exatamente o trecho que chama atenção de Foucault é referente a uma certa enciclopédia chinesa:

Esas ambigüedades, redundancias y deficiencias recuerdan las que el doctor Franz Kuhn atribuye a cierta enciclopedia china que se titula Emporio celestial de conocimientos benévolos. En sus remotas páginas está escrito que los animales se dividen en (a) pertenecientes al Emperador, (b) embalsamados, (c) amaestrados, (d) lechones, (e) sirenas, (f) fabulosos, (g) perros sueltos, $(\mathrm{h})$ incluidos en esta clasificación, (i) que se agitan como locos, (j) innumerables, (k) dibujados con un pincel finísimo de pelo de camello, (l) etcétera, (m) que acaban de romper el jarrón, (n) que de lejos parecen moscas. (BORGES, 2015, s. p.; FOUCAULT, 2007: IX)

Segundo Foucault, seu livro nasce justamente estranhamento causado por estas categorias tão díspares e desconcertantes, que parecem, aos nossos olhos acostumados às classificações 
tradicionais do pensamento ocidental, não serem dotadas de lógica alguma. Porém, se realmente "no hay clasificación del universo que no sea arbitraria y conjetural", o riso de Foucault é gerado não pela inexatidão, e sim pelo estranhamento do contato com algo completamente distinto, ou seja, o contato com a alteridade e suas categorias, suas estruturas, que não podem ser pensadas a partir das nossas próprias estruturas, fazendo do estranhamento, ao fim, a sensação acre que resta após o choque da relação conflituosa entre o Mesmo e o Outro, acompanhado simultaneamente de uma comicidade e de um mal-estar.

Este último, obviamente, causado não pelos elementos elencados, e sim pela proximidade sem ordem aparente na qual se misturam seres reais e fantásticos, presentes ou ausentes, desconsiderando estas antinomias sobre as quais se baseia a epistèmê do Ocidente.

Foucault cita o exemplo dos afásicos, que padecem de uma condição que os impede de classificar determinadas coisas, como novelos de lã de diferentes cores sobre uma mesa, por exemplo. A imagem da mesa funciona como metáfora perfeita para a epistèmê moderna, especialmente ao pensarmos sua exigência quase quimérica de cientificidade, pois é exatamente isso o que estas categorias de pensamento fazem, elas não se dedicam à compreensão do mundo como um todo em sua complexidade, e sim a catalogar e organizar mediante categorias predeterminadas, geralmente arbitrárias, os elementos que estão em um campo de trabalho em geral exageradamente delimitado, como a mesa do exemplo de Foucault. A produção dos saberes se dá, portanto, com um processo de criar distinções, ao invés de estabelecer relações. Superando a avaliação que se pode ter feito inicial e ingenuamente a respeito da enciclopédia chinesa e direcionando-a a nossas próprias categorias de pensamento e organização, Foucault percebe igualmente e arbitrariedade dos sistema de classificação.

Em que "tábua", segundo qual espaço de identidades, de similitudes, de analogias, adquirimos o hábito de distribuir tantas coisas diferentes e parecidas? 
Que coerência é essa - que se vê logo não ser nem determinada por um encadeamento a priori e necessário, nem imposta por conteúdos imediatamente sensíveis. (FOUCAULT, 2007: XV)

Percebemos então a afinidade entre Borges e Foucault na medida em que ambos consideram que é uma ordem previamente estabelecida o que sustenta a organização do pensamento e ordena, por vezes aproximando, por outras separando, os diversos elementos que fazem parte do cabedal conceitual de determinada cultura. Este esquematismo prévio é responsável por criar não apenas a ordem empiricamente expressada como, igualmente e talvez até com mais força, a própria ideia de ordem, a necessidade ontológica de ordenação e organização que está em germe no pensamento científico ocidental, o de que, compreendendo o ordenamento das coisas, se pode desenvolver a previsibilidade dos fenômenos como meio de dominação do mundo e controle. Tal constatação muda radicalmente o conceito de gênio, ou mesmo de autoria como um processo autônomo e independente, desvinculado do contexto e das categorias dentro das quais as produções materiais e intelectuais são geradas. Na medida em que o sujeito é transpassado pelas diversas categorias de pensamento relativas à cultura na qual ele surge e que lhe é pré-existente. Dessa forma, os autores são os cristalizadores das categorias de pensamento de suas respectivas épocas, seus corroboradores ou detratores, mas sempre estão, ainda que não tenham disso clareza, operando em relação ao que lhes antecede e excede.

Os códigos fundamentais de uma cultura - aqueles que regem sua linguagem, seus esquemas perceptivos, suas trocas, suas técnicas, seus valores, a hierarquia de suas práticas - fixam, logo de entrada, para cada homem, as ordens empíricas com as quais terá de lidar e nas quais se há de encontrar. (FOUCAULT, 2007: $\mathrm{XVI})$. 
E é isso, aliás, o que nos possibilita pensar o Quixote como a objetificação literária das transformações na epistèmê do século XVII, e não os criadores de algo oriundo do nada absoluto. Esta é a razão pela qual, para citar um outro texto de Borges, seria um exercício intelectual fútil e inócuo que Pierre Meinard tenha tentando compor, como queria, o seu Quixote no início do século $\mathrm{XX}$, pois ele estaria descontextualizado do momento históricocultural no qual surgiu pela mão de Cervantes nos albores do século XVII e das diversas transformações da epistèmê das quais esta obra dá testemunho ainda que indiretamente. (BORGES, 1997, p. 52 e 53) Tais transformações deixam bem claro que não há uma submissão absoluta ao ordenamento anterior, pois, se assim fosse, a cultura seria um homogeneidade estável, e não a eterna sucessão de continuidades e rupturas, convivências paralelas no tempo e no espaço e disputas pela hegemonia: é justamente neste contexto de transformação, neste sfumato limítrofe entre o que foi e o que ainda será, que reside a arqueologia do saber de Foucault e a possibilidade de entendermos a passagem de um ordenamento a outro.

Assim, entre o olhar já codificado e o conhecimento reflexivo, há uma região mediana que libera a ordem no seu ser mesmo: é aí que ela aparece, segundo as culturas e segundo as épocas, contínua e graduada ou fracionada e descontínua, ligada ao espaço ou constituída a cada instante pelo impulso do tempo, semelhante a um quadro de variáveis ou definida por sistemas separados de coerências, composta de semelhanças que se aproxima sucessivamente, ou se espelham mutuamente, organizada em torno de diferenças crescentes, etc. (FOUCAULT, 2007: XVII)

O objetivo de Foucault é, portanto, desnudar essas relações e essas ordens desde o século XVI e perceber como tais mudanças criam a realidade sobre a qual se fundamenta o conhecimento de nossos dias. Porém, passa muito ao largo de ser uma história das ciências, pois isso seria como querer desvelar o que já está, de 
antemão, desnudado, e sim uma arqueologia das ciências humanas, como propriamente se define o texto a partir de seu subtítulo, para por sob a luz aquilo que geralmente se esconde na metáfora do fundamento, do alicerce, ou seja, o que dá a base e a estrutura das ciências sem nunca estar a descoberto, o seu ordenamento, a "experiência nua da ordem e de seus modos de ser".

[...]; o que se quer trazer à luz é o campo epistemológico, a epistèmê onde os conhecimentos, encarados fora de qualquer critério referente a seu valor racional ou a suas formas objetivas, enraízam sua positividade e manifestam assim uma história que não é a de sua perfeição crescente, mas, antes, a de suas condições de possibilidade; [...]. (FOUCAULT, 2007: XVIII)

Um dos dois momentos que são identificados nesta obra como de transição epistemológica é o da idade clássica, ou seja, a passagem do século XVI ao XVII, que poderíamos entender igualmente como a transição do Renascimento ao Barroco, período correspondente à escrita e publicação da primeira e da segunda parte de Dom Quixote, em 1605 e 1615, respectivamente. Nesse caso, o que nos compete identificar não é mais aquele estranhamento com uma ordem completamente diferente, como no caso do ensaio de Borges, e sim aquilo que está subjacente a um ordenamento que, de alguma forma, ainda corresponde em diversos casos ao nosso mesmo, pelo menos em sentido genealógico.

Trata-se, em suma, de uma história da semelhança: sob que condições o pensamento clássico pôde refletir, entre as coisas, relações de similaridade ou de equivalência que fundam e justificam as palavras, as classificações, as trocas? [...]; a história da ordem das coisas seria a história do Mesmo - daquilo que, para uma cultura, é ao mesmo tempo disperso e aparentado, a ser portanto distinguido por marcas e recolhido em identidades. (FOUCAULT, 2007, p. XXII) 
O texto de Cervantes, o primeiro romance no formato como o conhecemos hoje, é emblemático dessa transformação. Ele se situa exatamente no ponto de ruptura de um ordenamento que visava a interconexão de todas as coisas a partir de categorias de semelhança para um sistema de pensamento calcado na, para lembrar um conceito filosófico barroco contemporâneo à obra, mônada como modelo da existência individual, que, apesar de radicalmente apartada de tudo, adquire a sua importância ontológica na medida em que se entende como nó relacional em meio a uma multidão de outros indivíduos que se entendem apenas em relação ao lugar que ocupam na organização catalográfica dos entes e à distância que os separa de todos os outros sujeitos, igualmente isolados e interconectados, num prenúncio à nossa própria subjetividade pós-moderna.

A ficção frustrada das epopeias tornou-se no poder representativo da linguagem. As palavras acabam de se fechar na sua natureza de signos. Dom Quixote é a primeira das obras modernas, pois que aí se vê a razão cruel das identidades e das diferenças desdenhar infinitamente dos signos e das similitudes: pois que aí a linguagem rompe seu velho parentesco com as coisas, para entrar nessa soberania solitária donde só reaparecerá, em seu ser absoluto, tornada literatura; [...]. (FOUCAULT, 2007:67)

Entretanto, antes de percebermos a nossa condição de diferenciação, é necessário, inclusive para facilitar o entendimento por oposição, compreendermos o que era o mundo sob o véu da semelhança.

\section{2 - A doutrina das semelhanças}

Os modelos de pensamento do século XVI eram dados pelo padrão das semelhanças, pela relação de simpatia entre as coisas. Opensamento, então, teria a possibilidadee a tarefa de, investigando a natureza, descobrir, desvelar as relações das coisas entre si, tanto no que tinham de aproximação natural, a simpatia, quanto de 
repulsão, no caso da antipatia natural entre os seres. E esse modelo não era exclusivo do comportamento humano, como igualmente extensível a todas as coisas. Os minerais se relacionavam, quase voluntariamente, com outros minerais, mas também com os homens segundo seu temperamento, com outros animais, com os vegetais e com os planetas. $\mathrm{O}$ mundo era organizado em grandes categorias que amalgamavam itens em seu interior mediante um critério de aglutinação e relação mágica. Foucault abre com estas palavras o seu capítulo sobre A Prosa do Mundo:

Até o fim do século XVI, a semelhança desempenhou um papel construtor no saber da cultura ocidental. [...] O mundo enrolava-se sobre si mesmo: a terra repetindo o céu, os rostos mirando-se nas estrelas e a erva envolvendo em suas hastes os segredos que serviam ao homem. A pintura imitava o espaço. E a representação - fosse ela festa ou saber - se dava como repetição: teatro da vida ou espelho do mundo, tal era o título de toda linguagem, sua maneira de anunciarse e de formular seu direito de falar. (FOUCAULT, 2007: 23)

O conhecimento era erigido, portanto, como representação verossímil do mundo, como no exemplo da obsessão renascentista pela perspectiva e pela anatomia, pois estava subentendido que o intelecto poderia desvendar os liames invisíveis entre as coisas e penetrar a obscuridade secreta da natureza. A linguagem, nesse caso, cumpre o papel de permitir adequadamente o acesso e a transmissão desse saber conquistado sobre o mundo. Em outras palavras, era no mundo, nas coisas fora dele mesmo, que o intelecto buscava a fundamentação do conhecimento, contrastando com a radicalidade do sujeito solipsista, a hipertrofiada subjetividade moderna de origem cartesiana.

A similitude, modelo de relação entre o intelecto e o mundo, podia se apresentar em quatro formas não excludentes: convenientia, aemulatio, analogia e simpatia. Foucault usa textos da 
época para elencar estas modalidades, como a Syntaxeon Artis Mirabilis, de Grégoire, publicada em Köln em 1610; La Physionomie humaine e Magie Naturelle de Giovanni Porta, publicada em 1655; de Umberto Aldrovandi a Mostrorum Historia de 1647; de Tomaso da Campanella, um dos poucos autores mais conhecidos dentre estes citados, Realis Philosophia, publicado em Frankfurt em 1623; Liber Paramirum, do alquimista Paracelso, escrito no século XVI; entre outros. Poder elencar como base para a pesquisa de Foucault estes textos tão pouco conhecidos de nossa cultura só vem a reafirmar o método arqueológico em oposição ao histórico, pois o que se busca é justamente o obscuro, o que não está revelado.

Ainda que muito próximas em sua definição conceitual, as quatro categorias da semelhança, justamente por estarem assim tão nitidamente categorizadas, dão conta do processo de pensamento por catalogação de semelhanças do qual são simultaneamente exemplo e definição. A convenientia é a aproximação espacial e gradual das coisas em suas relações, de forma que seus limites se misturem sutilmente, que o fim de uma vá dando vazão ao surgimento de outra. Ela representa a cadeia de pensamentos que liga uma planta a um peixe, este peixe a um planeta, o planeta a uma doença humana e esta a uma outra planta, numa concatenação virtualmente infinita. A proximidade espacial própria da convenientia é rompida, porém, na aemulatio. Esta é a relação entre duas coisas que não se tocam, como se o elas tivessem entre si uma conexão secreta capaz de agir à distância. É propriamente emulação, ou seja, fazer com que o que está presente valha ou represente o que está ausente.

Enquanto convenientia e aemulatio estão pautadas nas relações entre os seres, a analogia permite estabelecer relações entre as próprias relações, ou seja, evocando sua etimologia, fazer falar através das coisas, é a similitude das relações das coisas com os ambientes nos quais se encontram, as proporções através das quais eles se organizam.

Mas destas relações, que poderiam estar deslocadas e dispersas por entre todos os seres e todas as conexões entre eles, está um ponto fixo: o homem. Através dele todas as relações 
não apenas passam como são exclusivamente compreendidas, ele é o detentor do poder de analogia para a interpretação e compreensão do mundo, o que já antecipa, de certa forma, a guinada que o pensamento dará logo após, tanto em seu mergulho no sujeito solipsista cartesiano, para o qual apenas ele tem existência confirmada por necessidade lógico-racional, quanto no perspectivismo empirista a partir do qual o mundo existe apenas enquanto percepção dos sentidos deste sujeito privilegiado pelo entendimento, diferentemente do que nos dá a epistèmê clássica que quer o conhecimento como uma representação do mundo independentemente daquele que o contempla.

Por fim temos a quarta categoria, a mais abrangente, a da simpatia, bem como de sua antagonista, a antipatia. Por esta razão ela é a mais ampla das categorias de semelhança, pois não está limitada nem no tempo nem no espaço, é uma forma universal generalizada de assimilação relacional, permitindo que o entendimento estabeleça os vínculos entre as diversas criaturas infinitamente, bem como explica a ação dos seres em si mesma, mesmo dos corpos inanimados ou dos planetas. Porém, ela deve ser contrabalanceada pela antipatia, para impedir que em sua força de assimilação e atração das diferentes coisas em função de suas similaridades, ela transforme o mundo inteiro em uma homogeneidade. A antipatia preserva a individualidade dos seres que permite o seu reconhecimento da força de atração de sua contrária.

Todas estas relações existentes não seriam perceptíveis ao intelecto humano se não fosse pelas assinalações que as interconectam simbolicamente, permitindo então que nossa percepção desvende as relações mágicas, remotas e inexplicáveis entre os objetos afins. Apesar de as relações nos dizerem como o mundo se organiza e interconecta, elas não nos dizem como reconhecer estas conexões, exceto pelas marcas que as coisas ostentam, pelas assinalações que nos indicam qual o caminho trilhado pelas semelhanças.

Decifrar as similitudes é, portanto, um processo de conhecimento e, ao mesmo tempo, de poder sobre o mundo 
das coisas, de maneira que as assinalações sejam aquilo que, na doutrina das semelhanças, mais exposto e, paradoxalmente, mais recôndito se encontra. As assinalações guardam profunda e íntima relação com a linguagem, exceto pelo fato de que o texto humano, a linguagem escrita, não tenha o mesmo poder hieroglífico da linguagem da natureza, ou seja, não seja capaz de controle mágico sobre as coisas, apenas comunique aquilo que é resultado de convenção semântica, e não a verdade profunda por trás das coisas. As assinalações explicam aquilo que para a nossa subjetividade contemporânea é estranho, que uma determinada planta seja indicada para curar a doença de determinado órgão do corpo humano a partir da imagem impressa em suas folhas, que lembra o formato do órgão em questão. Essa relação da semelhança com o sinal que a designa enquanto também uma relação de semelhança torna o processo de interpretação infinito, o que Foucault exemplifica bem ao analisar o quadro de Velázquez, Las Meninas (1656), logo no início de seu livro.

Nosso autor vai definir este esforço de interpretação no pensamento clássico como simultaneamente uma hermenêutica e uma semiótica, de maneira que, enquanto a primeira interpreta os símbolos em seu contexto semântico, a segunda possa localizá-los e definí-los enquanto tais.

Esse "vão" é justamente o aspecto que faz com que Dom Quixote seja tão importante para a literatura ocidental, pois é a primeira obra a ser realizada a partir dessa nova epistèmê, ou seja, não vai mais estabelecer a relação das palavras com as coisas e sim das palavras com elas mesmas, pois não é a transformação do mundo em narrativa, e sim seu revés, a transformação de narrativa em mundo que será seguida pela narrativa dela mesma, em um processo de auto-refração que já identificamos no quadro de Velázquez.

Foucault chama essa configuração de conhecimento de pletórica, pois ela não estabelece uma relação direta de conhecimento senão que encadeia as coisas em correntes infinitas de relações que não explicam as coisas em suas identidades, 
senão de forma relacional a todas as demais coisas com as quais ela estabelece relação de semelhança. A erudição aparece então como uma categoria interessante do conhecimento, na medida em que é justamente a acumulação mnemônica que ela possibilita que fundamenta o desvendamento das assinalações presentes nas coisas e permite a decifração de suas simpatias e semelhanças, conveniências e emulações, seja na infinidade factual da natureza ou no labirinto referencial das bibliotecas, ou, dito de outra maneira, tanto na epistèmê do Renascimento quanto do Barroco. Isso traz ao pensamento a metáfora do livro do mundo que é a natureza, disponível em seus segredos àqueles que saibam decodificar seus símbolos explícitos para chegar a seus conhecimentos escondidos. Daí a importância da linguagem no pensamento clássico, como meio de decifração do mundo e também como coisa a ser decifrada enquanto palavra mesma.

No século XVI, a linguagem real não é um conjunto de signos independentes, uniforme e liso, em que as coisas viriam refletir-se como num espelho, para aí enunciar, uma a uma, sua verdade singular. [...] No seu ser bruto e histórico do século XVI, a linguagem não é um sistema arbitrário; está depositada no mundo e dele faz parte porque, ao mesmo tempo, as próprias coisas escondem e manifestam seu enigma como uma linguagem e porque as palavras se propõe aos homens como coisas a decifrar. (FOUCAULT, 2007: 47)

Nem exata, nem arbitrária, a linguagem faz parte do grande sistema das assinalações e permite o conhecimento do mundo na medida de sua correspondência com as coisas de acordo com um código secreto, sagrado, primordial, a conexão entre o mundo e a sua nomeação permitida aos homens por Deus antes da punição pela Torre de Babel. Daí o poder das palavras mágicas, daí o estudo das línguas mortas, daí o poder do discurso sobre o mundo. Mas este conhecimento está perdido, restando à humanidade apenas conjuntos de assinalações imprecisas, línguas que não estabelecem com força a relação entre as palavras e as coisas que representam e 
que, cientes dessa incapacidade, só podem adotar dois caminhos: esforçar-se conscientemente em vão para restabelecer essa conexão, o que de certa forma contextualiza o desespero barroco em relação ao conhecimento, ou abandonar a necessidade de representação do mundo e estabelecer a linguagem como algo que tem seu fundamento a partir da relações de si para consigo, num alheamento progressivo do mundo a representar que chega aos píncaros da glosa universal.

Saber consiste, pois, em referir a linguagem à linguagem. Em restituir a grande planície uniforme das palavras e das coisas. Em fazer tudo falar. Isto é, em fazer nascer, por sobre todas as marcas, o discurso segundo do comentário. $\mathrm{O}$ que é próprio do saber não é nem ver nem demonstrar, mas interpretar. (FOUCAULT, 2007: 55)

E, na sua tentativa de reestabelecer a relação primitiva, a linguagem se torna interpretação infinita, pois só pode enunciar aquela verdade perdia acercando-se dela, circunscrevendo-a de sentidos e versões. Neste ponto Foucault cita, muito apropriadamente, e em tom quase profético a respeito da produção cultural do ocidente, incluindo esta nossa aqui presente, Montaigne: "Há mais a fazer interpretando as interpretações que as coisas; e mais livros sobre livros que sobre qualquer outro assunto; nós não fazemos mais do que nos entreglosar." (MONTAIGNE apud FOUCAULT, 2007: 56) A linguagem, portanto, passa a ser infinita como a perseguição do horizonte, pois ela sempre está anunciando um sentido que está mais além dela mesma enquanto enunciação. Tal separação é, claramente, a mudança da linguagem como representação para a linguagem como enunciação, ou seja, não há mais um mundo a ser representado pela linguagem, tampouco a possibilidade de que ela o representasse caso ele viesse a existir novamente, de forma que a tarefa que ela assume doravante é a da enunciação não do mundo que é, e sim do mundo que ela cria, que ela acha que deve ser. Não mais discurso, e sim literatura. 
Nada mais há em nosso saber e em nossa reflexão que nos traga hoje a lembrança desse ser. Nada mais, salvo talvez a literatura - e ainda de um modo mais alusivo e diagonal que direto. Pode-se dizer, num certo sentido, que a "literatura" tal como se constituiu e assim se designou no limiar da idade moderna, manifesta o reaparecimento, onde era inesperado, do ser vivo da linguagem. (FOUCAULT, 2007: 59 e 60)

É neste ponto que surge, como modelo da literatura moderna ocidental, como cristalização desta transformação do pensamento, Dom Quixote, permitindo, segundo Roberto Machado (2000, p. 28) que o pensamento renascentista estabeleça um jogo com a loucura que não necessariamente se oponha de forma radical à sanidade e à verdade e que vai se desenvolver ao longo da modernidade de maneira a permitir intuirmos uma grande verdade dentro das alucinações da loucura.

\section{3 - A nossa triste figura}

No romance de Cervantes se estabelecem pela primeira vez relações diferentes entre a linguagem e o mundo, momento no qual se abandonam as antigas relações entre as coisas, suas semelhanças e os signos que as marcam novas relações emergem na epistèmê ocidental moderna, de maneira a constituir-se tanto na primeira obra do classicismo quanto na ultima obra da renascença.

Tal transformação, por sua vez, deve-se a um movimento de recuo, movimento pelo qual Dom Quixote passa a ocupar um espaço intermediário entre o da loucura e o da linguagem, espaço em que terá condições de contribuir para a formação do conceito mais geral de epistèmê, bem como dos conceitos mais particulares de analogia e representação. (CALMON, 2003: 116) 
O protagonista é chamado de "o herói do Mesmo", exemplificando o que já havia sido colocado a respeito da linguagem, que a narrativa de Cervantes se desenvolve sob o signo da auto-referência, não mais uma linguagem que aponta para o mundo e sim um sistema de signos que se volta sobre si mesmo em um processo infinito e infindável. Novamente: a linguagem, representada aqui pela literatura, não mais representa o mundo, senão que o enuncia e, nesse processo, recorre a si mesma como fundamentação, transformando aquilo que deveria representar. Por isso Dom Quixote recorre aos livros e a suas histórias de cavalaria para descobrir como o mundo deve ser, para guiar-se em suas ações, pois o seu acesso direto ao mundo foi barrado pela rede imperscrutável da linguagem.

Mas, se ele quer ser-lhes semelhante, é porque deve prová-los, é porque os signos (legíveis) já não são semelhantes a seres (visíveis). [...] Cabe-lhes refazer a epopeia, mas em sentido inverso: esta narrava (pretendia narra) façanhas reais prometidas à memória; já Dom Quixote deve preencher com realidade os signos sem conteúdo da narrativa. (FOUCAULT, 2007:64)

Dom Quixote não faz mais uma leitura do mundo que será colocada nos livros, senão ao contrário, uma leitura dos livros para interpretar o mundo. Nesse sentido, ele inverte radicalmente o pensamento renascentista, pois a linguagem deixou já de ser representação adequada do mundo. Ela pode ser doravante apenas uma representação fantasiosa, dele, momento no qual o moinho será um gigante porque é isso que está nos livros, os rebanhos de carneiros serão um exército de inimigos, a camponesa será uma dama. (CALMON, 2003:125)

É pois de saber que este fidalgo, nos intervalos que tinha de ócio (que eram os mais do ano), se dava a ler livros de cavalarias, com tanta afeição e gosto, 
que se esqueceu quase de todo o exercício da caça, e até da administração de seus bens; e a tanto chegou a sua curiosidade e desatino neste ponto, que vendeu trechos de terra de semeadura para comprar livros de cavalaria que ler, com o que juntou em casa quantos pode apanhar daquele gênero. (CERVANTES, 1981: 31)

Tudo isso porque nessa nova configuração do pensamento, os textos são mais importantes, têm mais poder de efetivação, do que a realidade empírica. Em seu desenvolvimento a linguagem não representa mais o mundo que se vê, senão que cria alucinadamente o mundo que deseja. Tal esquizofrenia epistemológica passa a ser a base do pensamento ocidental moderno, criando a clivagem radical entre as palavras e as coisas.

[...] a história de Dom Quixote de la Mancha é a história da ascensão de uma outra epistèmê, a representação, que, na passagem da Renascença para o período clássico, justamente quando o romance foi escrito e publicado (1605 a 1615), passa a substituir a velha ordem de saber baseada na analogia, [...]. (CALMON, 2003: 131)

Porém, ao passo que as coisas não são mais do que elas são, individual e isoladamente, não representando nenhuma semelhança, nenhuma analogia, da mesma forma as palavras erram vazias de significado imediato. A linguagem ganha a sua independência do mundo ao voltar-se para seu isolamento interior ao sujeito moderno que, como veremos, apesar de absoluto, se encontrará solipsista e potencialmente ensandecido.

Em suma, tanto naquelas leituras se enfrescou que passava as noites de claro em claro e os dias de escuro em escuro, e, assim, de pouco dormir e muito ler, se lhe secou o cérebro, de maneira que chegou a perder o juízo. (CERVANTES, 1981: 32) 
Percebamos que a mesma condenação que nossa subjetividade contemporânea faz em relação aos delírio do Cavaleiro da Triste Figura, alinhando-se ao seu fiel escudeiro para rir de sua inventividade e nobre ingenuidade, é a crítica que fazemos ao pensamento das relações universais invisíveis das semelhanças entre as coisas cristalizadas no conjunto de conhecimentos da magia e da erudição. Ou seja, desacreditamos uma visão "não científica do mundo", que crê em bruxas, poções do amor e astrologia, sem percebermos que ela não é a-científica no sentido de não pertencer a um conjunto coerente e sistêmico de organização dos conhecimentos e pensamentos, e sim que ela pertence a um modelo epistemológico diferente do nosso, a uma outra ordenação da enciclopédia celestial de saberes benévolos, por assim dizer.

O louco, entendido não como doente, mas como desvio constituído e mantido, como função cultural indispensável, tornou-se, na experiência ocidental, o homem das semelhanças selvagens. [...] É o jogador desregrado do Mesmo e do Outro. Toma as coisas pelo que não são e as pessoas umas pelas outras; ignora seus amigos, reconhece os estranhos; crê desmascarar e impõe uma máscara. (FOUCAULT, 2007: 67)

Duas alternativas se descortinam então à frente deste pensamento das semelhanças, uma é a loucura, como acabamos de demonstrar, e a outra é a poesia e a literatura, nas quais igualmente se reconhecem as relações entre as coisas, as metáforas que as unem, os significados obscuras que elas escondem. Essa pode ser base da conexão entre poesia e loucura na produção cultural da modernidade ocidental, mas não em forma de um delírio inspirado, e sim como capacidade epistemológica de reconhecimento das semelhanças entre as coisa em um mundo de elementos radicalmente isolados.

Às margens de um saber que separa os seres, os signos e as similitudes, e como que para limitar seu poder, 
o louco garante a função do homossemantismo: reúne todos os signos e os preenche com uma semelhança que não cessa de proliferar. $O$ poeta garante a função inversa; sustenta o papel alegórico; sob a linguagem dos signos e sob o jogo de suas distinções bem determinadas, põe-se à escuta de 'outra linguagem', aquela, sem palavras nem discursos, da semelhança. (FOUCAULT, 2007: 68)

Mas algo a mais no romance de Cervantes, o romance por excelência, acontece: ele se dobra sobre si mesmo, ele se fecha no círculo infinito da auto-referência no momento em que personagens da segunda parte do livro entram em cena tendo já lido a primeira parte, libertando o cavaleiro da observação dos romances de cavalaria alheios e prendendo-o ao seu próprio texto, de maneira que a literatura, que já não representava o mundo, não faça referência a uma outra narrativa, senão a si mesma. Espanta-se e alegra-se Dom Quixote ao saber que as suas andanças haviam sido escritas por um "mouro e sábio", Cide Hamete Benengeli, e publicadas sob o nome de O Engenhoso Fidalgo Dom Quixote de La Mancha em Lisboa, Barcelona e Valencia:

\begin{abstract}
Uma das coisas - acudiu Dom Quixote - que maior contentamento deve dar a um homem virtuoso e eminente é o ver andar-se em vida pela bocas do mundo, impresso e com estampa com bom nome, é claro, porque, sendo ao contrario, não há norte que se lhe iguale. (CERVANTES, 1981: 234)
\end{abstract}

Dessa maneira, fecha-se o círculo sobre o qual se encerrará a linguagem e o sentido, pois transforma-se em personagem $o$ homem que queria viver da mesma maneira que os personagens que admirava, e transforma-se em narrativa a vida que imitava as narrativas, em um espelhamento infinito que ilustra os labirintos dentro dos quais vai se desdobrar errante o pensamento barroco. É isto que faz de Dom Quixote, definitivamente, o herói do Mesmo. A transformação da epistèmê que esta obra exemplifica traçou 
a separação radical entre as palavras e as coisas, entre o mundo e as suas representações, entre o sujeito e o objeto. Isso não equivale a dizer, obviamente, que antes de Dom Quixote as narrativas eram enunciações da verdade e depois passaram a ser vãs fantasias, pois, de acordo com Marthe Robert (2007, p. 26 et seq.), a narrativa em geral, e o romance em particular, nunca é especificamente uma representação da verdade, senão que uma criação incessante de um outro, de uma alteridade epistemológica que pode, como estamos sugerindo, perder-se em si mesma, como no exemplo de Dom Quixote.

[...]: o romance nunca é verdadeiro nem falso, fazendo apenas sugerir um ou outro, isto é, dispondo sempre exclusivamente da escolha entre duas maneiras de enganar, entre duas espécies de mentira [...]. (ROBERT, 2007:100)

É isto que torna o romance, como gênero, e especialmente Dom Quixote, como modelo deste gênero, objetos de reflexão tão polissêmicos, pois eles simultaneamente se relacionam ao mundo no qual acontecem e ao palco que criam e recriam e não se contentam com o mero representar, verdadeira ou falsamente, o mundo, senão que, como forma de narrativa e fabulação, auxiliam mesmo a criar o mundo que representam. Superando a mera representatividade das narrativas anteriores, Dom Quixote inaugura uma narrativa que vai se desdobrar sobre si mesma, fazendo se si o objeto de reflexão.

Porém, seja como for, o romance não existe mais sem a fissura que deve agora enfrentar; pelo menos não há mais história pretensamente verdadeira que não escolha como tema os conflitos do herói consigo mesmo em seu aprendizado da vida. (ROBERT, 2007:36 et seq.)

Dessa maneira, todos nós, cujas subjetividades vão atravessadas por este modelo e por tais rupturas, em nosso esforço 
alucinatório para a compreensão do mundo, investimos, lança em riste, contra nossos próprios moinhos de vento. Somos todos Dom Quixote. O significado do mundo se nos ausenta. Enquanto isso, erramos. "A escrita e as coisas não se assemelham mais. Entre elas, Dom Quixote vagueia ao sabor da aventura." (FOUCAULT, 2007: 66).

\section{Referências}

BORGES, J. L. El Idioma Analítico de John Wilkins. Disponível em: $<$ http://languagelog.ldc.upenn.edu/myl/ldc/wilkins.html>. Acessado em: 10 jun. 2015.

. La Biblioteca de Babel. In: Ficciones. Madrid: Alianza Editorial, 1997, p. 86 - 99.

. Pierre Menard, autor del Quijote. In: Ficciones. Madrid: Alianza Editorial, 1997, p. 41 - 55.

CALMON, J. O Dom Quixote de Foucault. Rio de Janeiro: E-Papers Serviços Editoriais Ltda, 2003.

CERVANTES E SAAVEDRA, M de. Dom Quixote de La Mancha. Tradução Visconde de Castilhos e Azevedo. São Paulo: Victor Civita, 1981.

FOUCAULT, M. As Palavras e as Coisas: Uma arqueologia das ciências humanas. [Les Mots et les Choses] Tradução de Salma Tannus Muchail. 9a ed. São Paulo: Martins Fontes, 2007.

MACHADO, R. Foucault, a Filosofia e a Literatura. Rio de Janeiro: Jorge Zahar, 2000.

ROBERT, Marthe. Romance das origens, romance. São Paulo: Cosac Naify, 2007. 